\title{
Analysis of irrigation system performance based on an integrated approach with Sentinel-2 satellite images
}

\author{
Meriem Er-Rami, ${ }^{1}$ Guido D'Urso, ${ }^{2}$ Nicola Lamaddalena, ${ }^{1}$ Daniela D'Agostino, ${ }^{1}$ Oscar Rosario Belfiore ${ }^{2}$ \\ ${ }^{1}$ Department of Land and Water Resources Management, CIHEAM-Mediterranean Agronomic Institute of Bari, \\ Valenzano (BA); ${ }^{2}$ Department of Agricultural Sciences, University of Naples Federico II, Portici (NA), Italy
}

\begin{abstract}
The improvement of performance of irrigation systems plays a fundamental role in increasing their efficiency in order to reach a sound use of irrigation water. The COPAM (Combined Optimization and Performance Analysis Model) has proven its usefulness in performance evaluation of on-demand irrigation systems; however, in many cases, input data, such as water volumes delivered by hydrants, is not readily available. To support a wider application of the COPAM, we tested the possibility of using irrigation volumes estimated by means of space-borne remote sensing. The Sentinel-2 (S2) constellation provides high spatial resolution images with a frequency between 2 and 5 days, which is compatible with COPAM input requirements.

In the present work, an irrigation sector in the Capitanata irrigation network (Foggia Province, no. 6 of District 10) in Italy was chosen to assess its performance by using COPAM with volumes estimated from Sentinel-2 data. As an input of COPAM, the upstream discharge was determined after a proper transformation of the estimated irrigation water requirement volumes and the
\end{abstract}

Correspondence: Meriem Er-Rami, Department of Land and Water Resources Management, CIHEAM-Mediterranean Agronomic Institute of Bari, via Ceglie 9, 70010 Valenzano (BA), Italy.

E-mail: meriemremi96@gmail.com

Key words: COPAM; crop evapotranspiration; irrigation water requirement; on-demand irrigation system; performance analysis; Sentinel-2 images.

Acknowledgements: this research is carried out within the framework of the EO-TIME 'Earth Observation Technologies for Irrigation in Mediterranean Environments' project financed by the ERANETMED3 UE Program.

Contributions: NL, GD, conceptualization and supervision; MER, GD, $\mathrm{NL}, \mathrm{DD}, \mathrm{ORB}$, methodology and manuscript revision; MER, ORB, data acquisition and analysis; MER writing original draft preparation. All authors read and agreed to the published version of the manuscript.

Received for publication: 16 March 2021.

Accepted for publication: 6 May 2021.

${ }^{\circ}$ Copyright: the Author(s), 2021

Licensee PAGEPress, Italy

Journal of Agricultural Engineering 2021; LII:1170

doi:10.4081/jae.2021.1170

This article is distributed under the terms of the Creative Commons Attribution Noncommercial License (by-nc 4.0) which permits any noncommercial use, distribution, and reproduction in any medium, provided the original author(s) and source are credited. recorded volumes into flowrates. The estimation of the irrigation water requirement volumes was accomplished through the estimation of crop evapotranspiration, Etc $\mathrm{c}_{\mathrm{rop}}$, and effective precipitation, $\mathrm{P}_{\mathrm{n}}$, by combining crop parameters (leaf area index - LAI, fractional vegetation cover - fc, and Albedo) derived from S2 images and the meteorological data from the ERA5 single levels reanalysis dataset collected for the whole study period, from June $1^{\text {st }}$ to September $30^{\text {th }}, 2019$. The study comprised a comparison of the estimated irrigation water volumes and the corresponding recorded volumes. The results showed a good agreement between the estimated and the registered volumes in a large time scale for 10 days and a one-month period, while a large difference was observed in a daily time scale. The performance analysis was carried out for the overall system and at hydrant level. The estimated discharge was lower than the registered discharge, indicating better performance. Last but not least, some recommendations were proposed for improving performance in critical zones.

\section{Introduction}

In the $21^{\text {st }}$ century, agriculture continues to be a fundamental activity for sustainable development, poverty reduction and food security all over the world. As the world population is set to increase in future, so will the demand for food. In order to meet this growing demand, the entire world, and especially arid and semi-arid regions will require a significant expansion and intensification of irrigation agriculture (Ozdogan et al., 2010).

However, irrigated agriculture requires the highest amount of water resources which accounts for $70 \%$ of the total water use (UNWAP, 2016), therefore the increase of water productivity in agriculture will play a vital role in conserving this scarce source. Several countries, especially those with a arid and semi-arid climate, are tackling these problems by adopting pressurized irrigation systems instead of open channels. In order to maintain as much efficiency as possible, performance analysis of irrigation systems is required to improve management activities and identify appropriate modernization or rehabilitation measures (Lamaddalena and Pereira, 2007). Recently, many computer simulations models have been developed to reach this purpose such as COPAM (Lamaddalena, 1997), EPANET (Rossman, 2000), GESTAR (Estrada et al., 2009). These models have been designed by different researchers and based on their own modelling principles to fulfil performance analyses of on-demand pressurized irrigation systems (Kurtulmus et al., 2018). In the current research, the COPAM (Combined Optimization and Performance Analysis Model) software will be used as a tool to assess the performance analysis of pressurized irrigation systems operating on-demand. This model was chosen because it is reliable and has been already applied worldwide for the same objective of this study. The use of its different modules is simple and can perform analyses at network level and at hydrant level thanks to two included models 
(ICARE and AKLA). It also performs a stochastic analysis. Nevertheless, in many cases, the input data for COPAM such as the water volumes delivered at hydrants level are not readily available. For this purpose, using the estimated irrigation volumes by means of space-borne remote sensing could help and support the performance analysis of the irrigation systems. Moreover, remote sensing with varying degree of accuracy has been able to provide information on land use, irrigated area, crop type, biomass development, crop yield, crop water requirements, crop evapotranspiration, salinity, etc. (Bastiaanssen, 1998).

Maps of biophysical vegetation parameters combined with agro-meteorological data are used at country or regional level to derive crop water needs from satellites (D'Urso et al., 2010).

Crop parameters such as leaf area index (LAI), fractional vegetation cover $\left(\mathrm{f}_{\mathrm{c}}\right)$, and Albedo can be estimated using earth observation (EO) data, which is presently available for free on openwebsites access, and high-spatial resolution data, during the crop growth cycle. This can be done at time intervals suitable for the detection of changes in crop phenology in order to determine crop growth cycle characteristics, improve the identification of each growth cycle stage, which is often undetectable when lower temporal resolution data are used (Rolim, 2019).

Several satellites are now in earth orbit and are designed to measure measuring certain terrestrial processes. As each satellite has its own overpass characteristics in terms of return period, local overpass time, pixel size and number of spectral bands, satellite applications vary (Bastiaanssen et al., 2000). Recently, new earth observation (EO) satellites have been developed, and have the potential to improve remote sensing such as Sentinel-2.

The Sentinel-2A\&B satellites carry on-board the multi-spectral instrument (MSI) for acquisitions in 13 spectral bands spanning from the visible and near-infrared (VNIR) to the short-wave infrared (SWIR), featuring 4 spectral bands at $10 \mathrm{~m}, 6$ bands at 20 $\mathrm{m}$ and 3 bands at $60 \mathrm{~m}$ spatial resolution (https://sentinels.copernicus.eu/web/sentinel/user-guides/sentinel-2-msi/resolutions/spatial). Using the satellite images, an estimation of crop parameters, mainly LAI and fractional vegetation cover $\left(f_{c}\right)$, will be done taking into account crop development. The calculation of crop evapo- transpiration and net precipitation, which is based on the estimated crop parameters and on daily meteorological data, will be used to calculate crop irrigation water requirements. By transforming these volumes into flow rates, performance analysis of pressurized irrigation system could be conducted. The advantage in this case is that the irrigation demand is actually linked to crop development as detected from satellites. The main objective of this study is to assess the possibility of using satellite images to monitor the performance of irrigation systems and conduct the following: i) estimation of irrigation water requirements using remote sensing; ii) comparing the estimated irrigation requirements and the corresponding water volumes withdrawn at the sector level; iii) analysing the hydraulic performance of the irrigation system by using the discharges calculated using the above-mentioned methodologies; iv) setting up a number of recommendations for rehabilitating and managing irrigation systems.

\section{Materials and methods}

\section{Study area}

The study area is sector 6 of Irrigation District 10 (Figure 1) in the 'Sinistra Ofanto' irrigation scheme, located in Southern Italy in the north-eastern part of Apulia region (province of Foggia). The irrigation scheme is part of the area managed and operated by the 'Consorzio per la Bonifica della Capitanata (CBC)', one of largest irrigation water users' associations in Italy.

District $10\left(41^{\circ} 16^{\prime} 49.2 \mathrm{~N} 16^{\circ} 03^{\prime} 57.1 \mathrm{E}\right)$ is divided into $19 \mathrm{sec}-$ tors, with a topographic area of 2000 ha. Our study focused on Sector no.6, which covers an area of 139 ha and has an irrigated area of around 100 ha. The average farm size ranges from 0.4 to 2.5 ha and there is a very high number of small land holdings.

The climate in this area is semiarid to sub-humid and is defined as 'Maritime-Mediterranean', which is the typical climate of the coastal areas of the Mediterranean region. The average yearly precipitation rate is about $500 \mathrm{~mm}$ and rainfalls are poorly distributed

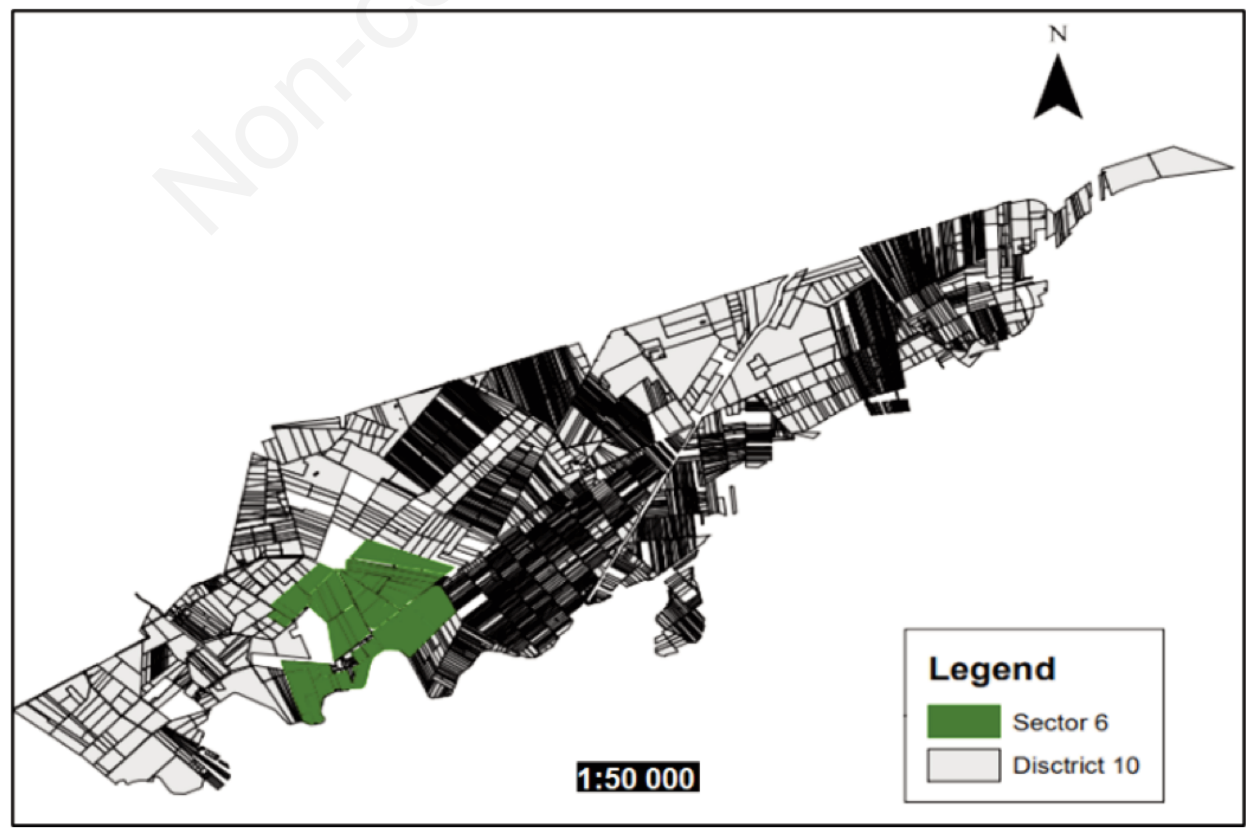

Figure 1. Sector 6 of irrigation in District 10. 
throughout the year. The average minimum temperature ranges from $3{ }^{\circ} \mathrm{C}$ in January to $19^{\circ} \mathrm{C}$ in July and August, while the maximum average temperature spans from $13^{\circ} \mathrm{C}$ in January to $33^{\circ} \mathrm{C}$ in July and August.

\section{Cropping pattern}

The most important species grown in sector 6 are vineyards, peaches and cereals. Figure 2 shows the cultivated area and its rel- ative spatial distribution in 2019 (data were obtained from CBC).

\section{Irrigation system}

A head unit is mounted at the head of the sector. The network which distributes the irrigation water to the farms is installed downstream to the head unit, and consists of buried PVC pipelines with diameters ranging from 110 to $250 \mathrm{~mm}$. Figure 3 shows a general scheme of the irrigation network.

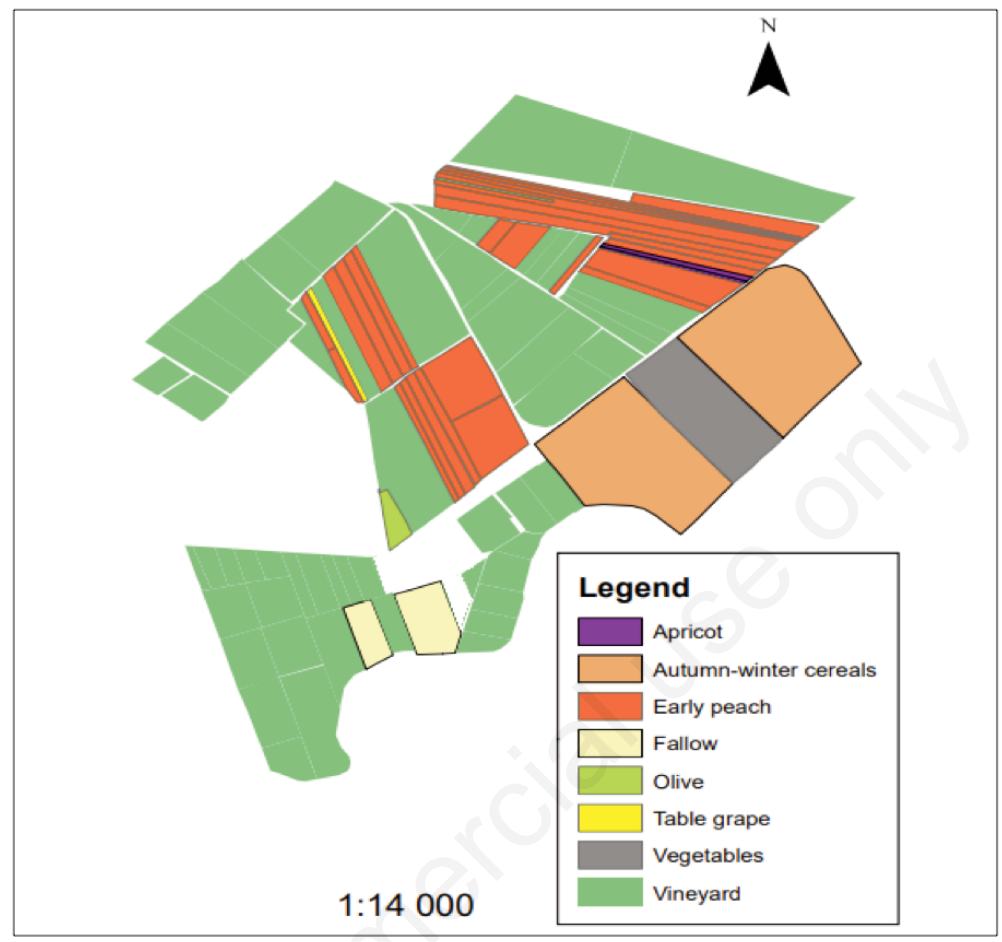

Figure 2. Cropping pattern map of Sector 6 in District 10.

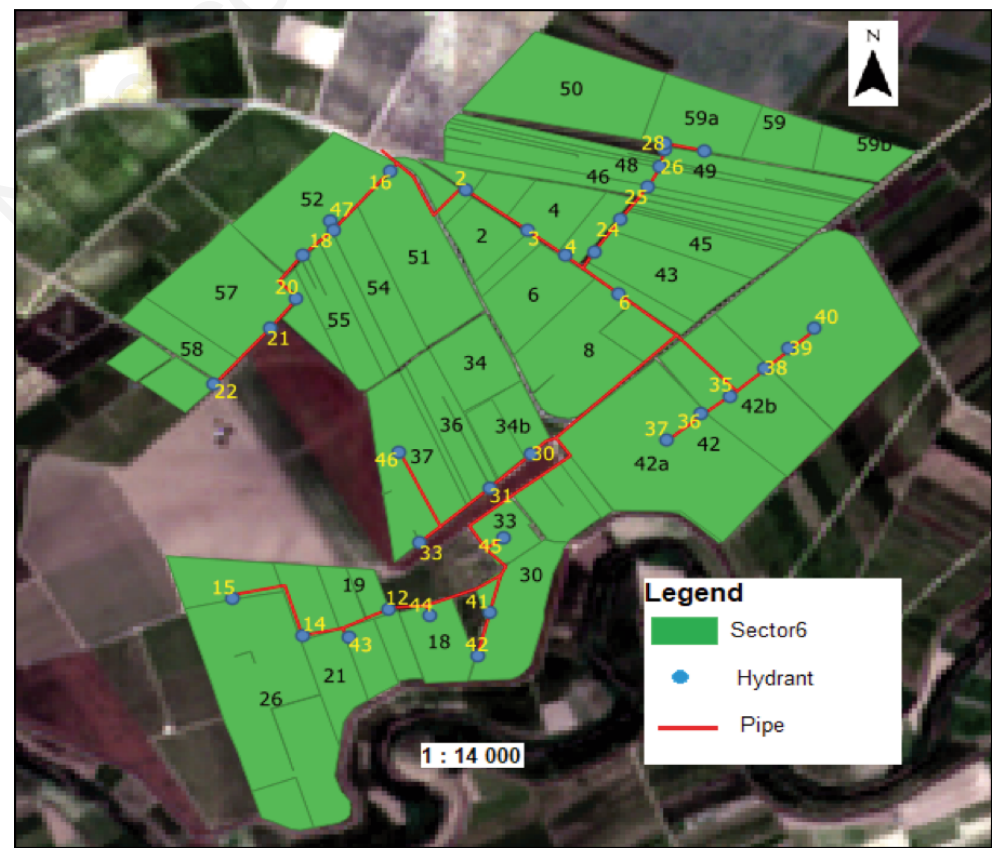

Figure 3. Layout of the irrigation network in Sector 6 (year 2019). 
Irrigation water is delivered to farms through 36 hydrants with a 10 l/s nominal discharge. Each one of these hydrants includes a gate valve, a flow regulator with a flow limiting pilot and a flow meter. The hydrants also have an electromechanical component which can distribute water only to the authorized users who use an electronic card.

\section{Dataset}

The data collection is a mandatory stage which instrumental to any study. Therefore, in order to initiate this study, which run from June $1^{\text {st }}$ to September $30^{\text {th }} 2019$, different kind of qualitative and quantitative data were acquired from various sources:

- Sentinel-2A (S2A) and Sentinel-2B (S2B), from the European Space Agency (ESA; https://sentinel.esa.int/web/sentinel/missions/sentinel-2), were chosen as satellite image data sources to analyse the agricultural land and generate the maps based on crop parameters.

- The meteorological data for applying Penman Monteith for the study period were derived from the ERA5 single levels reanalysis dataset (Hersbach et al., 2018; CDS; https://cds.climate.copernicus.eu/cdsapp\#!/home). ERA5 data, properly converted from the hourly scale to the daily scale, were considered as a substitute for ground-based meteorological data, which include daily average temperature, daily rainfall data, daily average relative humidity, daily solar radiation, daily wind speed (Pelosi et al., 2020).

- The registered volumes at hydrant level during the whole study period were collected from the consortium during a visit to the $\mathrm{CBC}$ office.

\section{Methodological framework}

The elaborations performed in this study are depicted in the chart of Figure 4 and can be summarized as follows: i) estimation of crop parameters for calculation of daily ET and irrigation water requirements (IWR) from satellite images; ii) estimation of irrigation water flow and peak period corresponding to the IWR deter-
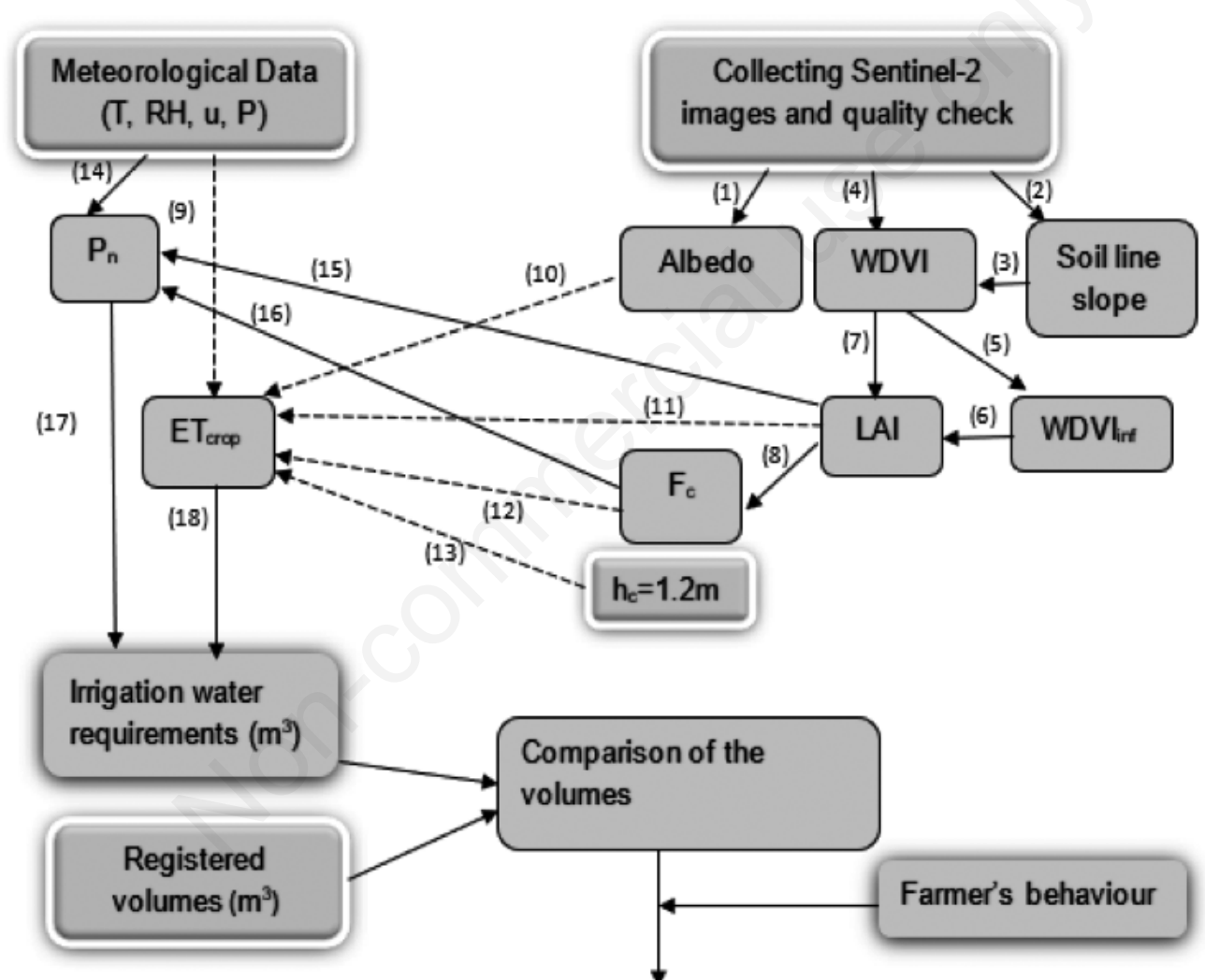

Farmer's behaviour

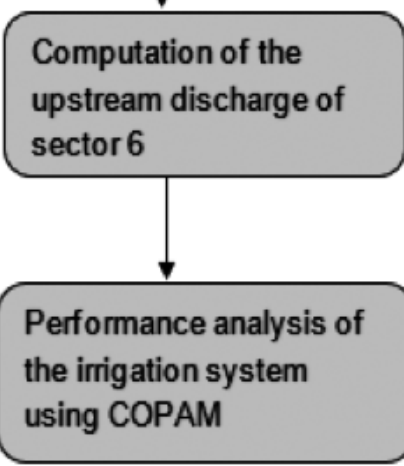

Figure 4. Methodological framework. 
mined in the previous step; iii) evaluation of the hydraulic performance of the irrigation distribution network.

\section{Data processing to derive earth observation-based crop parameters}

\section{Satellite images}

Earth observation images used to estimate crop parameters were collected from twin satellites Sentinel-2A and B of the European Space Agency (ESA). The nominal revisit time for the Sentinel-2 constellation is 5 days, however due to the overlap between swaths from adjacent orbits, the revisit frequency over the study area is increased to 2-3 days with different viewing conditions (The tile number field is T33TWF with two relative orbit numbers: 079 and 036). The satellite images for each band of Sentinel-2 (10 bands) of each available day for the whole study period (from first of June to September $30^{\text {th }} 2019$ ) were collected. The 10 bands have a different spatial resolution, therefore a $10 \mathrm{~m}$ resolution images were created by using the command 'Merge' of QGIS for each available date. This resulted into 40 satellite images, where two of them were eliminated after checking the cloud masks, which were also collected as a quality check that consisted in assessing the image data integrity and the presence of scattered clouds (normally images with clouds covering more than $20 \%$ of the image were rejected).

\section{Crop parameter maps}

Using the layer stack images for each available date, the crop parameter maps were generated by using the 'Raster Calculator' in the Raster menu. This menu makes it possible to perform calculations on the basis of existing raster pixel values and 'zonal statistics' in the processing toolbox of QGIS. This allows the calculation of some statistical values (mean values) for pixels of input raster inside certain zones defined as polygon layer. The crop parameter maps were created using the following equations.

\section{LAI}

LAI is a biophysical surface parameter defined as the total onesided area of photosynthetic tissue per unit of ground area (Bréda, 2003). There are several methods to estimate the LAI from satellite data. In this study we applied the so-called simplified Clevers' leaf area index by reflectance (CLAIR) model (Clevers, 1989), based on the weighted difference vegetation index (WDVI) as shown in the following relationship:

$$
L A I=-\frac{1}{\alpha} \ln \left(1-\frac{W D V I}{W D V I_{\infty}}\right)
$$

where WDVI is a radiometric index calculated for each pixel of the image from reflectance $\mathrm{r}_{\mathrm{RED}}$ and $\mathrm{r}_{\mathrm{NIR}}$ values respectively, in the red $(0.63-0.69 \mu \mathrm{m})$ and near infrared $(0.76-0.90 \mu \mathrm{m})$ bands using the following relationship:

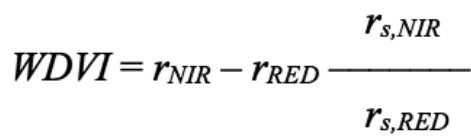

The $\frac{r_{S, N I R}}{r_{S, R E D}}$ ratio of near-infrared and red bare soil reflectance

is also known in the literature as the 'soil line slope'. Its value for the study area was 0.95 based on the analysis of reflectance in the nir and red for bare soil pixels within our study area. $\mathrm{WDVI}_{\infty}$ in Eq. (1) corresponds to the WDVI value for pixels with maximum vegetation cover and it is usually between 0.5 and 0.75 . In this study, its value is 0.53 , as identified from the WDVI histogram for the considered Sentinel-2 images.

In Eq.(1) $\alpha$ is an empirical shape parameter, mainly depending on canopy architecture, which was calibrated by using LAI calculated based on the inversion of a radiative transfer model by means of an Artificial Neural Network (Bacour et al., 2006). $\alpha$ is considered to be 0.5 in this study, which corresponds to the minimum error between the LAI_ANN and estimated LAI, as shown in Figure 5.

\section{Fractional vegetation cover (fc)}

The fractional vegetation cover $f_{c}$ is derived from the LAI using a polynomial empirical expression. Its coefficients are determined from field measurements and are valid for a wide range of crops $\left(\mathrm{LAI} \leq 5 \mathrm{~m}^{2} \mathrm{~m}^{-2}\right.$ ) (Vuolo et al., 2015), like the case of this present study. $f_{c}$ was calculated using the expression below:

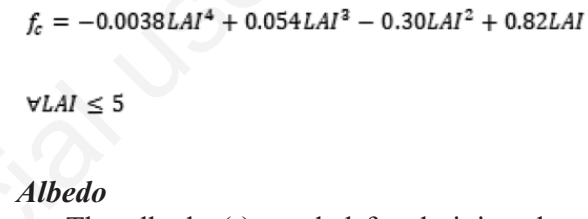

\section{Albedo}

The albedo (r) needed for deriving the net radiant flux is an approximation of the hemispherical and spectrally integrated surface albedo. Considering the limited spectral resolution of EO data normally available, the albedo is calculated as a weighted sum of surface spectral reflectance derived from the atmospheric correction, with broadband coefficients representing the corresponding fraction of the solar irradiance in each sensor band (D'Urso and Calera Belmonte, 2006):

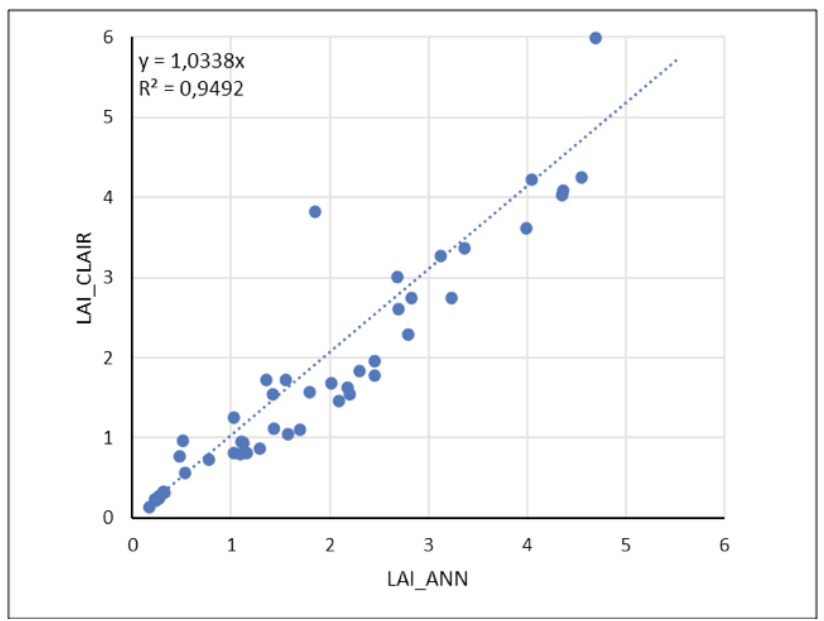

Figure 5. Calibration of LAI_Clair by means of LAI_ANN. 


$$
r=\sum_{\lambda=1}^{n} \rho_{\lambda} \omega_{\lambda}
$$

\section{Crop height $\left(h_{c}\right)$}

Crop height $h_{c}$ was fixed at $1.2 \mathrm{~m}$. The assumption made was

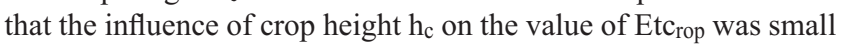
for different LAI values as proved in study conducted by Vuolo et al. (2015).

\section{Estimating Etcrop based on derived crop parameters}

The procedure was applied by integrating EO techniques and the meteorological data of the study area. The conceptualization was developed by D'Urso (2001) and applied to a vineyard in Apulia region by Vanino et al. (2015). The estimation of Etcrop under standard conditions - disease-free, adequate fertilization, and soil water availability - was carried out using the FAO PenmanMonteith method, which requires standard meteorological data such as solar radiation, air temperature, air humidity, wind speed, and crop biophysical parameters, such as albedo, LAI, and crop height, and using the canopy values for a hypothetical grass reference crop i.e. $\mathrm{h}_{\mathrm{c}}=0.12 \mathrm{~m} ; \mathrm{r}=0.23$ and $\mathrm{LAI}=2.88$. The resulting equation gives the reference crop evapotranspiration $\mathrm{ET}_{0}$.

The procedure is known as one-step approach and is computed as:

$E T_{\text {crop }}=\frac{86400}{\lambda}\left[\frac{\Delta\left(R_{n}-G\right)+\rho c_{p}\left(e_{s}-e_{a}\right) C_{a}}{\Delta+\gamma\left(1+C_{a} / C_{s}\right)}\right]$

where:

- Etc rop is crop evapotranspiration, expressed in $\mathrm{mmd}^{-1}$;

$-\lambda$ is the latent heat of vaporization of water $\left(\mathrm{J} \mathrm{kg}^{-1}\right)$;

- $\Delta$ is the slope of the saturated vapor pressure-temperature curve $\mathrm{e}_{\mathrm{s}}(\mathrm{T})\left(\mathrm{kPa} \mathrm{K}^{-1}\right)$;

$-\mathrm{R}_{\mathrm{n}}$ is the net radiation flux density $\left(\mathrm{W} \mathrm{m}^{-2}\right)$;

$-\mathrm{G}$ is the heat flux density into the soil $\left(\mathrm{W} \mathrm{m}^{-2}\right)$;

- $\rho$ is air density $\left(\mathrm{kg} \mathrm{m}^{-3}\right)$;

$-\mathrm{c}_{\mathrm{p}}$ is air specific heat $\left(\mathrm{J} \mathrm{kg}^{-1} \mathrm{~K}^{-1}\right)$;

- $\left(e_{s}-e_{a}\right)$ is the vapor pressure deficit $(\mathrm{kPa})$ at the given air temperature $\mathrm{T}_{\mathrm{a}}$;

$-\mathrm{C}_{\mathrm{a}}$ is the aerodynamic conductance for heat transport $\left(\mathrm{m} \mathrm{s}^{-1}\right)$;

$-\gamma$ is the thermodynamic psychrometric constant $\left(\mathrm{kPa} \mathrm{K}^{-1}\right)$;

- $\mathrm{C}_{\mathrm{s}}$ is the surface conductance $\left(\mathrm{m} \mathrm{s}^{-1}\right)$, depending on canopy transpiration and soil evaporation.

This model considered the canopy as a big leaf, with a surface area expressed by the LAI, a crop height $h_{c}$ and a hemispherical spectrally-integrated albedo $r$, which was needed to calculate $R_{n}$.

The two conductance terms $\mathrm{C}_{\mathrm{a}}$ and $\mathrm{C}_{\mathrm{s}}$ were calculated as the inverse of the resistances defined by Allen et al. (1998):

$$
C_{a}=\frac{k^{2} U}{\ln \left(\frac{z_{U}-d}{z_{0 m}}\right) \ln \left(\frac{z_{\tau}-d}{z_{0 h}}\right)}
$$

$$
\begin{array}{ll}
C_{s}=0.005 \text { LAI } & \forall L A I \leq 4 \\
C_{s}=0.02 & \forall L A I>4
\end{array}
$$

where:

- k is von Karman's constant (0.41);
- $\mathrm{ZU}$ and $\mathrm{zT}$ are respectively the measurement heights for windspeed and temperature, where $\mathrm{zU}=10 \mathrm{~m}$ and $\mathrm{zT}=2 \mathrm{~m}$;

- $\mathrm{d}$ is the zero-plane displacement height and it is equal to $2 \mathrm{~h}_{\mathrm{c}} / 3$; - $\mathrm{z} 0 \mathrm{~m}, \mathrm{z} 0 \mathrm{~h}$ represent the roughness lengths for momentum and heat respectively. They are estimated from canopy height $h_{c}$ (Brutsaert, 1982), where $\mathrm{z}_{0 \mathrm{~m}}=0.123 \mathrm{~h}_{\mathrm{c}}$ and $\mathrm{z}_{0 \mathrm{~h}}=0.0123 \mathrm{~h}_{\mathrm{c}}$.

The calculation of $E t c_{\text {rop }}$ for each day was performed in an Excel sheet taking into account the meteorological data and the crop parameters of the same day for the whole study period.

\section{Estimation of $\mathbf{P}_{\mathbf{n}}$}

In order to describe the amount of intercepted water from the plant surface, $\mathrm{P}_{\mathrm{n}}$ was calculated as a function of actual precipitation (P), LAI, and fractional vegetation cover. The semi-empirical model of interception (Braden, 1985) is described by the following relationship:

$$
P_{n}=P-a L A I\left(1-\frac{1}{1+\frac{f_{c} P}{a L A I}}\right)
$$

where a $(\mathrm{mm} / \mathrm{d})$ is an empirical parameter representing the crop saturation per unit of foliage area $(2.88 \mathrm{~mm} / \mathrm{d})$.

\section{Crop irrigation water requirements}

The standard approach proposed by the Food and Agricultural Organization (FAO) (Allen et al., 1998) for the calculation of irrigation water requirements (IWR) can be adapted to remote sensing data. IWRs are commonly calculated as follows:

$I W R=E T_{\text {crop }}-P_{n}$

Net irrigation water requirements should be transformed into gross irrigation water requirements (GIR) by dividing them by irrigation efficiency, which was supposed to be $90 \%$, because the application efficiency of farms was high due to drip irrigation used predominantly in the area.

\section{Determination of the peak-period and the upstream discharge of sector 6}

Since the hourly discharges at the upstream end of sector 6 are not available, it was assumed that the distribution of flow rates at the head of the sector had a similar pattern to the one at the head of the district. This assumption was based on the similar approach to irrigation management of farmers in district 10, considering that the distribution of crop types and farm sizes is similar.

On the basis of this assumption, recorded hourly discharges at the upstream end of district 10 for each day from July $7^{\text {th }}$ to August $30^{\text {th }} 2020$ were used to transform the estimated and recorded average volumes of the 10-day peak period into discharges.

Based on the moving average method used for these data, the peak period identified in 2020 was from 22 July until 31 July. The average hourly discharges $\left(\mu_{h}\right)$ at the upstream end of district 10 during the 10-day peak period were calculated and are shown in the hydrograph in Figure 6. As can be seen, there were some specific hours of the day in which farmers preferred to irrigate, according to their commitments, habits, social conditions and availability of pressure at their hydrants.

Then, the average hourly volumes withdrawn from the system (District 10) were calculated using the following relationship: 


$$
V_{h}=\mu_{h} \Delta \mathrm{t} / 1000\left(\mathrm{~m}^{3}\right)
$$

where:

$\mu_{h}$ is the average hourly discharge at the upstream end of District 10 in $1 / \mathrm{s}$ (Figure 6);

$\Delta \mathrm{t}=3600$ is the time steps hour used.

The total average volume withdrawn in the average day of the peak period was then computed:

$$
V_{T}=\sum_{h=1}^{24} V_{h}
$$

as well as the frequency distribution $\mathrm{f}$ of the hourly withdrawals:

$$
f_{h}=\frac{V_{h}}{\sum_{h=1}^{24} V_{h}}
$$

Based on the assumption that $f_{h}$ as calculated in Eq.12 expressed also the frequency distribution of hourly volumes at the upstream end of sector 6 , it was possible to derive the average hourly discharge hydrograph from the daily total volume $V_{\text {avr }}$ by means of the following equation:

$$
Q_{h}(l / s)=\frac{1000}{3600} V_{a v r}\left(m^{3}\right) f_{h}
$$

In this calculation $V_{\text {avr }}$ is the average daily estimated volume or the average daily recorded volume for the 10-day peak period, at the upstream end of sector 6 . Therefore, the resulting hydrograph is illustrated in Figure 7, and the peak discharge could be determined as follows:

$$
Q_{0}=\operatorname{Max}\left(Q_{h}\right)
$$

\section{Performance analysis of the irrigation system using COPAM}

As soon as the upstream discharge of sector 6 was determined, the performance analysis of the irrigation system could be carried out using COPAM, as described in details by Lamaddalena and Sagardoy (2000). The hydraulic performance of the irrigation system was calculated at the network level using the indexed characteristic curves model and at the hydrant level using the AKLA model.

The indexed characteristic curves model provides global analysis of the network, it offers an overview of performance and operation efficiency of the whole network, and represents the unsatisfied or the satisfied configurations in term of minimum pressure required. On the contrary, the AKLA model can be used to analyse performance at the level of each hydrant in the network, thus giving a measurement of the hydraulic performance of each hydrant.

\section{Results and discussion}

After calculating LAI, $\mathrm{f}_{\mathrm{c}}$ and Albedo for each irrigation unit for each day, the Etc $\mathrm{c}_{\mathrm{rop}}$ and consequently also $\mathrm{P}_{\mathrm{n}}$ were calculated, then the crop irrigation water requirements were estimated. An example of the spatial distribution of the satellite-based CWR map for July $2^{\text {nd }} 2019$ is shown in Figure 8.

\section{Daily and monthly irrigation volumes at sector level}

Figure 9 reports the daily comparison between estimated and registered irrigation volumes from June $4^{\text {th }}$ until September $30^{\text {th }}$ 2019. As can be noticed, there is a slight variation of estimated volumes day by day compared to registered volumes which display much more significant variations. This difference occurs because the estimation of the irrigation volumes is entirely based on satellite images and meteorological data, and does not take into account the operation of the distribution network.

Table 1 shows a good agreement between the monthly registered volumes and the estimated volumes during irrigation season. The estimated volumes based on satellite images indicate some over-estimation in June, July and September, and a slight underestimation in August.

The slight differences between recorded and estimated irriga-

Table 1. Monthly estimated versus registered irrigation volumes during the 2019 at the upstream end of sector 6 .

\begin{tabular}{lcc} 
Month Estimated volumes $\left(\mathrm{m}^{3}\right)$ & Registered volumes $\left(\mathrm{m}^{3}\right)$ \\
June & 69,009 & 58,964 \\
July & 83,030 & 76,186 \\
\hline August & 65,396 & 66,718 \\
September & 30,524 & 25,967 \\
\hline
\end{tabular}

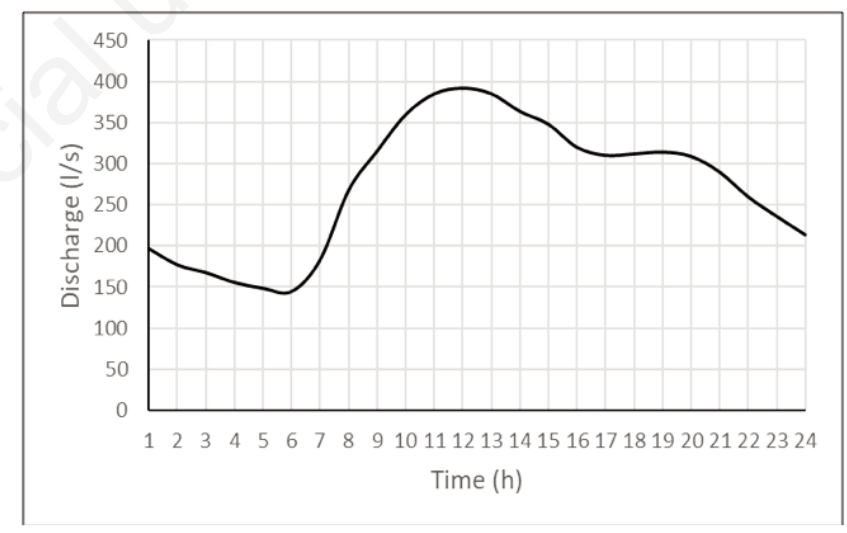

Figure 6. Hydrograph at the upstream end of District 10 during the 10-day peak period.

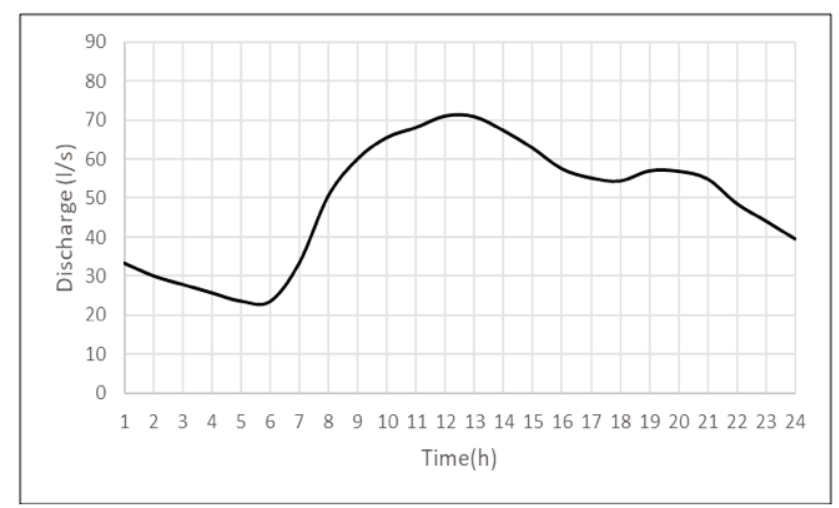

Figure 7. Hydrograph at the upstream end of sector 6 during the 10-day peak period. 
tion volumes during June and July may be explained by the shutoff for maintenance operations during the irrigation season. Conversely, in September the differences might be due to the reduction of irrigation by farmers at the end of the ripening stage of grapes wine in order to improve their sugar content and increase production quality.

\section{Irrigation volumes during the 10 -day peak period}

The moving average method was applied to the daily registered irrigation volumes withdrawn by the farmers and to the daily estimated volumes. The 10-day peak period identified from registration differs from that derived from satellite estimates by 1 day only (27 June to 6 July in the first, 28 June to 7 July in the latter).
Table 2 shows that the difference in the total irrigation volume during the 10-day peak period between the two sets is less than $9 \%$. However, the comparison of the daily estimated and registered irrigation volumes revealed a greater difference. The main reason for such difference is related to the operation of the distribution network, which envisaged more water withdrawals on days 3,4 and 5. Conversely, the satellite-based estimation would suggest a more uniform distribution which would be preferable from the agronomic point of view.

\section{Performance analysis of the irrigation system of sector 6}

Average hourly volumes and the total volume were calculated on the basis of Eq.10 and 11. As shown in Figure 7, the peak esti-

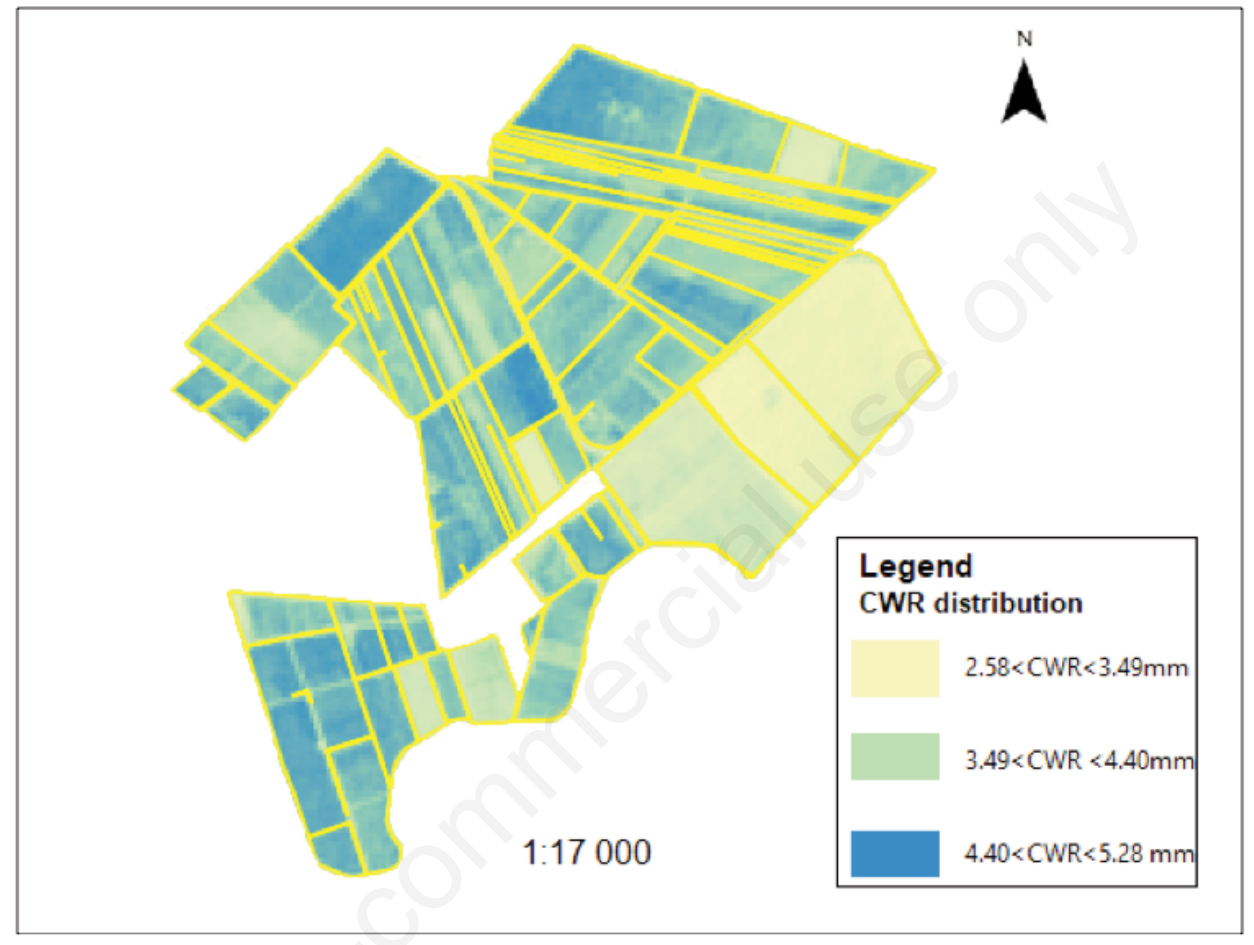

Figure 8. Map of crop water requirements (CWR) for sector 6 (July $2^{\text {nd }}$, 2019).

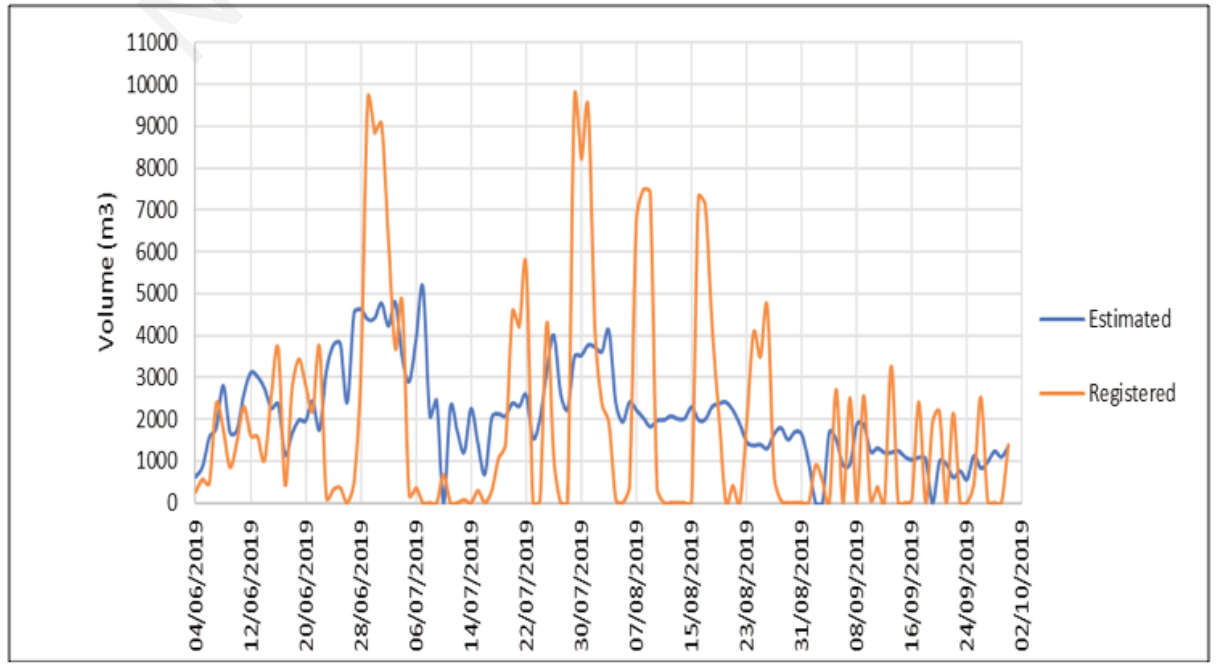

Figure 9. Daily estimated versus registered volumes at the upstream end of the sector. 
mated discharge was $71 \mathrm{l} / \mathrm{s}$. This value and the piezometric elevation of $100 \mathrm{~m}$. a.s.l. were used in the performance analysis of the irrigation system and would be achieved using COPAM through the two conceptual models: the indexed characteristic curve and AKLA model.

\section{Indexed characteristic curves model}

The indexed characteristic curves are represented in Figures 10 and 11. They were drawn using 200 random configurations of hydrants corresponding to upstream discharges $\mathrm{Q}_{0}$ between 10 and $1601 \mathrm{~s}^{-1}$.

Figure 10 shows that the set-point $\mathrm{P}_{01}(71,100)$ falls on the indexed curve of $91 \%$. This means that the head at the hydrants is higher than the minimum required $\left(\mathrm{H}_{\min }=20 \mathrm{~m}\right)$ in $91 \%$ of all the examined discharge configurations, whereas in Figure 11 the setpoint $\mathrm{P}_{02}(78,100)$ falls on the indexed curve of $85 \%$ which means that $85 \%$ of the investigated configurations are fully satisfied
Table 2. Estimated versus registered irrigation volumes at the upstream end of sector 6 during the 10-day peak periods.

\section{Days Estimated volumes $\left(\mathrm{m}^{3}\right) \quad$ Registered volumes $\left(\mathrm{m}^{3}\right)$}

\begin{tabular}{lcc}
1 & 4617 & 484 \\
2 & 4381 & 3137 \\
\hline 3 & 4411 & 9644 \\
4 & 4766 & 8836 \\
\hline 5 & 4222 & 9044 \\
6 & 4792 & 6291 \\
\hline 7 & 3473 & 3681 \\
8 & 2895 & 4778 \\
\hline 9 & 3906 & 181 \\
10 & 5152 & 353 \\
\hline Total & 42,615 & 46,429 \\
\hline
\end{tabular}

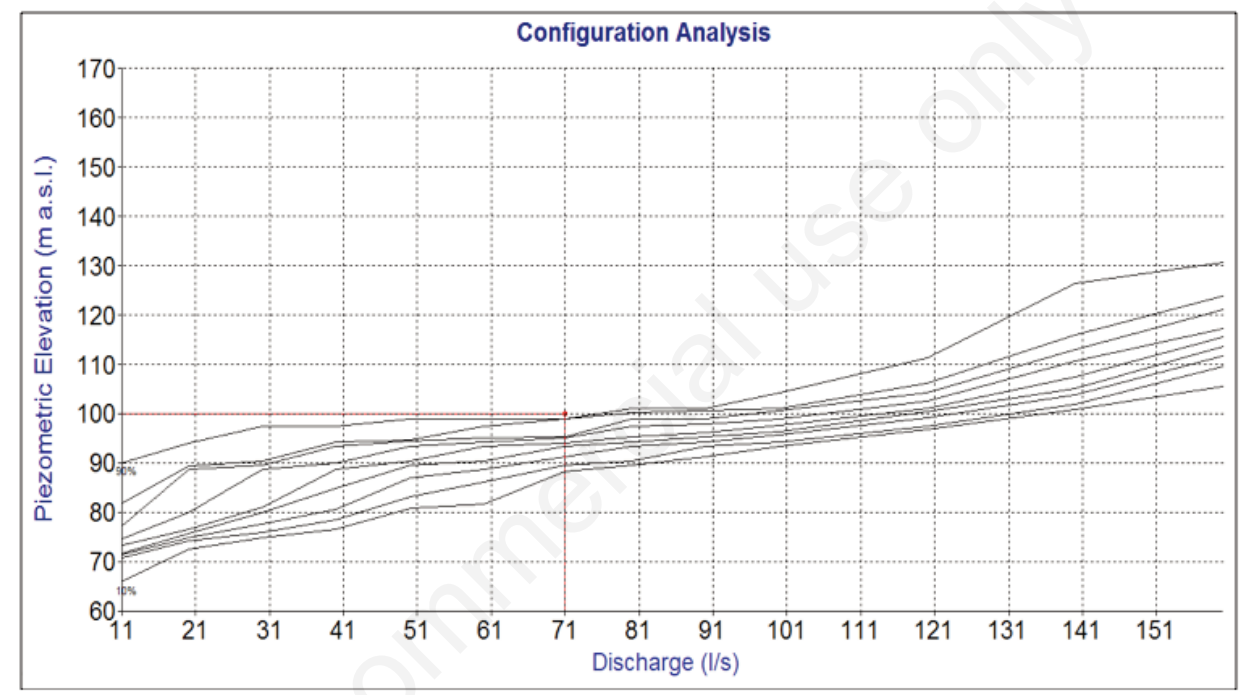

Figure 10. Indexed characteristic curve using 200 random configurations, $Q_{0}=71 \mathrm{l} / \mathrm{s}$ and $Z_{0}=100 \mathrm{~m}$ a.s.l.

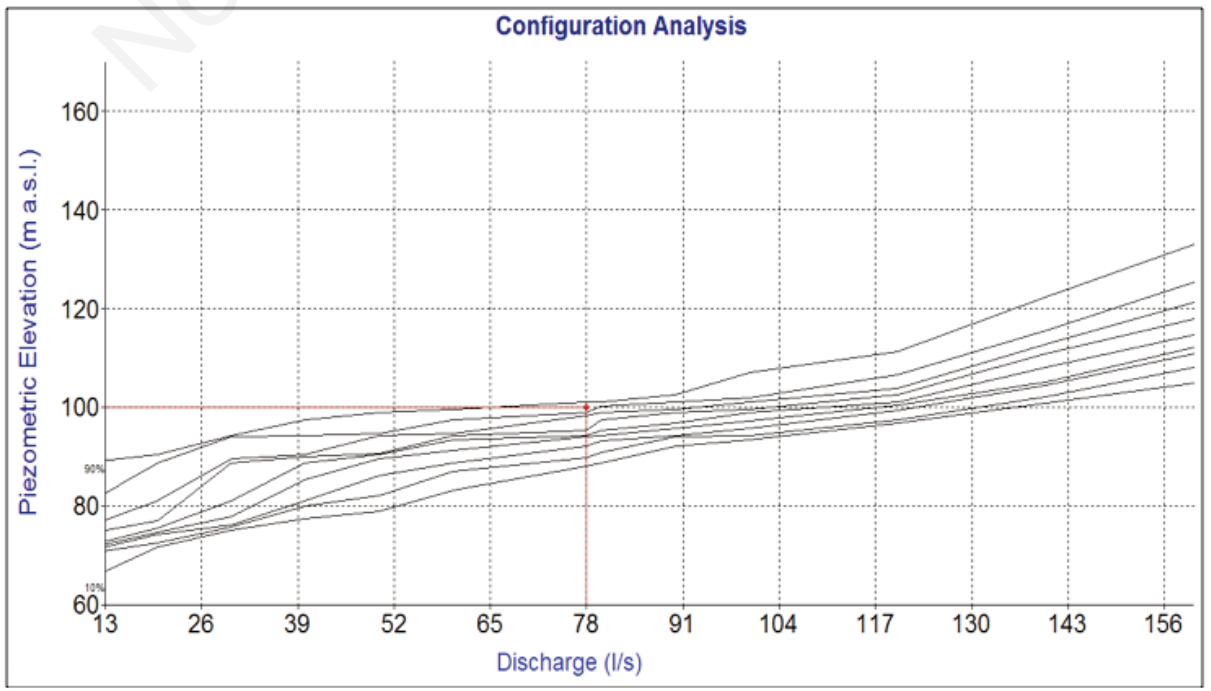

Figure 11. Indexed characteristic curve using 200 random configurations, $Q_{0}=78 \mathrm{l} / \mathrm{s}$ and $\mathrm{Z}_{0}=100 \mathrm{~m}$ a.s.l. 


\section{AKLA model}

\section{Relative pressure deficit}

Using 200 random configurations, the relative pressure deficit was tested using both discharges: the estimated discharge using satellite images of $71 \mathrm{1} / \mathrm{s}$ and the registered discharge of $78 \mathrm{l} / \mathrm{s}$.

i) Relative pressure deficit using the estimated upstream discharge: Figure 12 describes the relative pressure deficit using the estimated upstream discharge of 71 1/s. Figure 12A shows that for the whole set of investigated configurations it can be observed that the zones which are potentially subject to failure correspond to hydrants 16, 18,19, 21 and 22. These hydrants are the ones in less favourable elevations.

The $100 \%$ pressure deficit envelope curve indicated the variation of the relative pressure deficit at each hydrant in each discharge configuration, as is shown in Figure 12B with a relative pressure deficit of -0.3 for hydrant $19,-0.2$ for hydrants 16 and 18 and -0.1 for hydrants 21 and 22 .

$\mathbf{A}$

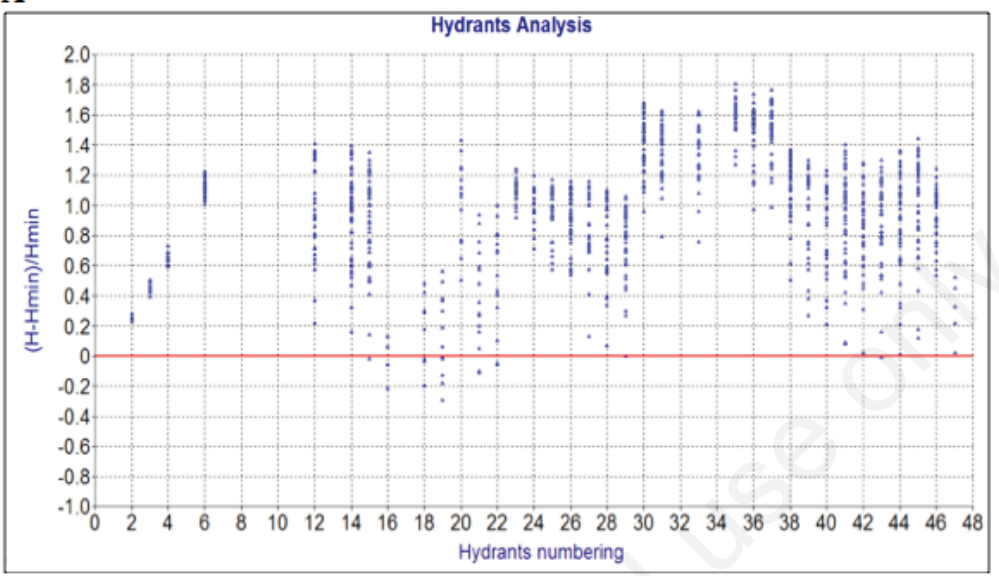

B

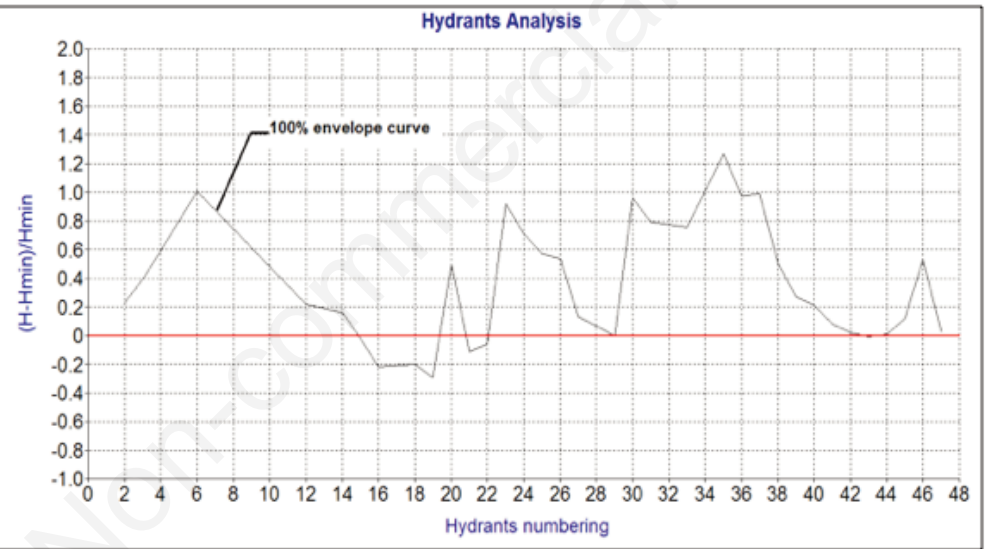

C

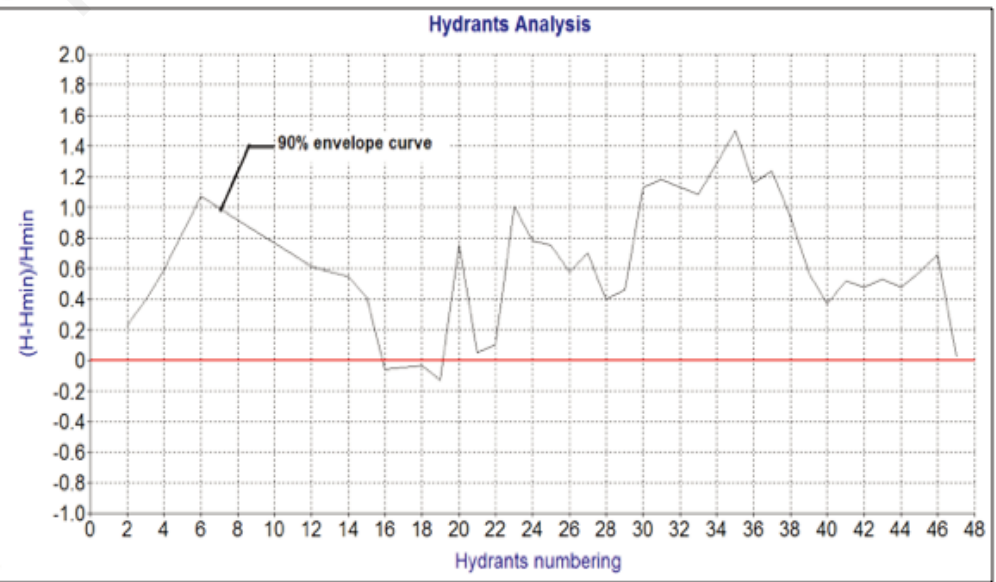

Figure 12. Relative pressure deficit results using $Q_{0}=711 / \mathrm{s}$ and $Z_{0}=100 \mathrm{~m}$ a.s.l. A) Relative pressure deficit of each hydrant at each configuration; B) $100 \%$ pressure deficit curve; C) $90 \%$ pressure deficit curve. 
The $90 \%$ pressure deficit curve (Figure 12C) is obtained by eliminating $10 \%$ of the most unfavourable points, and reveals that the most critical zones of the network are those of hydrants 16, 18 and 19 with a relative pressure deficit equal to -0.1 .

ii) Relative pressure deficit using the registered upstream discharge: Figure 13 shows the relative pressure deficit using the registered upstream discharge of $78 \mathrm{l} / \mathrm{s}$. As can be seen Figure 13A, for the whole set of investigated configurations, the zones which are potentially subject to failure correspond to hydrants $16,18,19$,

\section{1, 22, 27, 29 and 47.}

The $100 \%$ pressure deficit envelope curve indicated the variation of the relative pressure deficit at each hydrant in each discharge configuration, as shown in Figure 13B with a relative pressure deficit of -0.6 for hydrants 19 and $21,-0.5$ for hydrants 18 and $22,-0.4$ for hydrant $47,-0.2$ for hydrants 16 and 29 and -0.1 for hydrant 27.

By eliminating $10 \%$ of the most unfavourable points, the $90 \%$ pressure deficit curve (Figure 13C) shows that the most critical

A

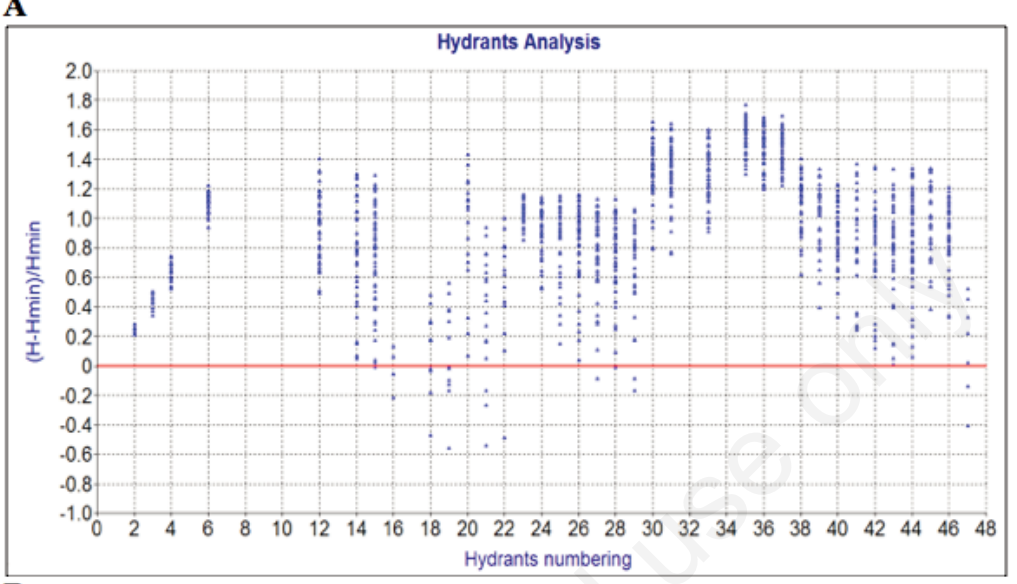

B

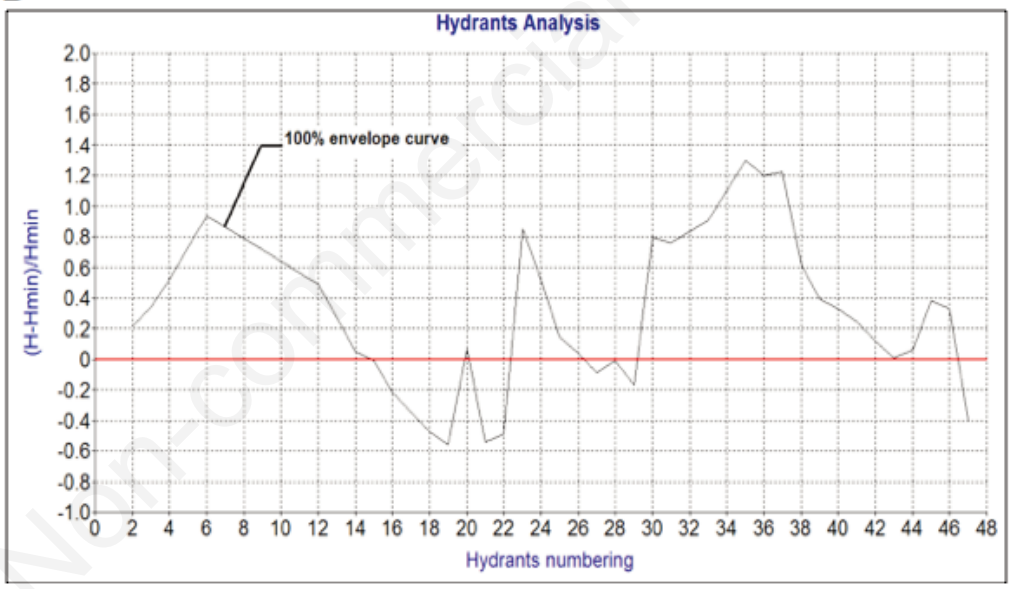

C

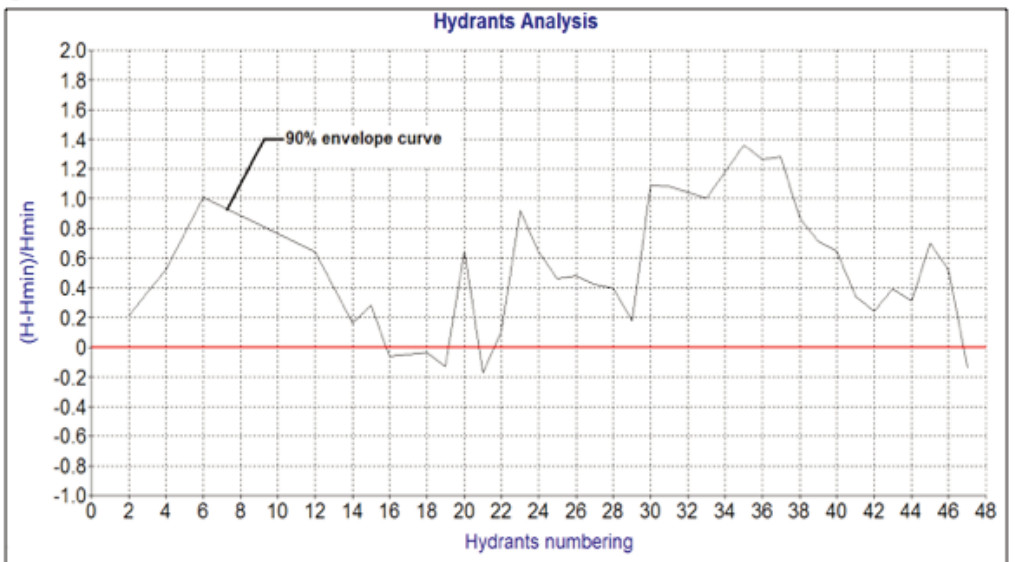

Figure 13. Relative pressure deficit results using $Q_{0}=78$ 1/s and $Z_{0}=100 \mathrm{~m}$ a.s.l. A) Relative pressure deficit of each hydrant at each configuration; B) $100 \%$ pressure deficit curve; C) $90 \%$ pressure deficit curve. 
zones in the network are those of hydrants 16, 18, 19, 21 and 47 with a relative pressure deficit below -0.2 .

Compared to Figure 12, the deficit increased for the hydrants which already had a pressure deficit, whereas other hydrants (27, 29 and 47) with an upstream discharge of 71 1/s were subject of pressure deficit.

\section{Reliability indicator}

The reliability of the system was evaluated applying 200 random configurations, and testing the estimated discharge and the registered discharge.

i) Reliability using the estimated upstream discharge: Figure 14 reports the reliability of each hydrant calculated using an estimated discharge of $71 \mathrm{l} / \mathrm{s}$ as upstream discharge. Reliability between 0.7 and 0.8 was observed for hydrants $16,18,19$, whereas hydrants 15 , 21, 22 and 43 had reliability values between 0.9 and 1 .

ii) Reliability using the registered upstream discharge: Figure 15 reports the reliability of each hydrant calculated using a registered discharge of $78 \mathrm{l} / \mathrm{s}$ as upstream discharge. A reliability between 0.6 and 0.7 was observed for hydrants 16 and 19 . Conversely, hydrants 18 and 47 ha a reliability between 0.8 and 0.9 , whereas hydrants $15,21,22,27,28$ and 29 had a reliability between 0.9 and 1 . It was also observed that the reliability value decreased compared with the reliability values calculated using the estimated discharge as shown in Figure 14.

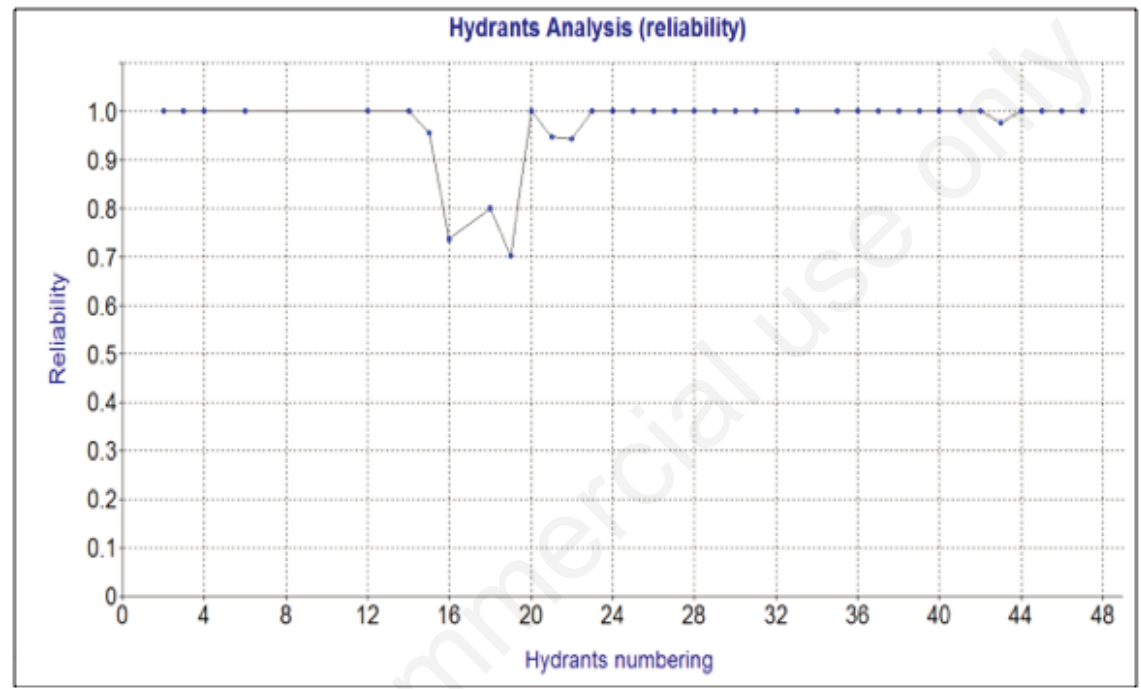

Figure 14. Reliability results using 200 random configurations, $Q_{0}=71 \mathrm{l} / \mathrm{s}$ and $Z_{0}=100 \mathrm{~m}$ a.s.l.

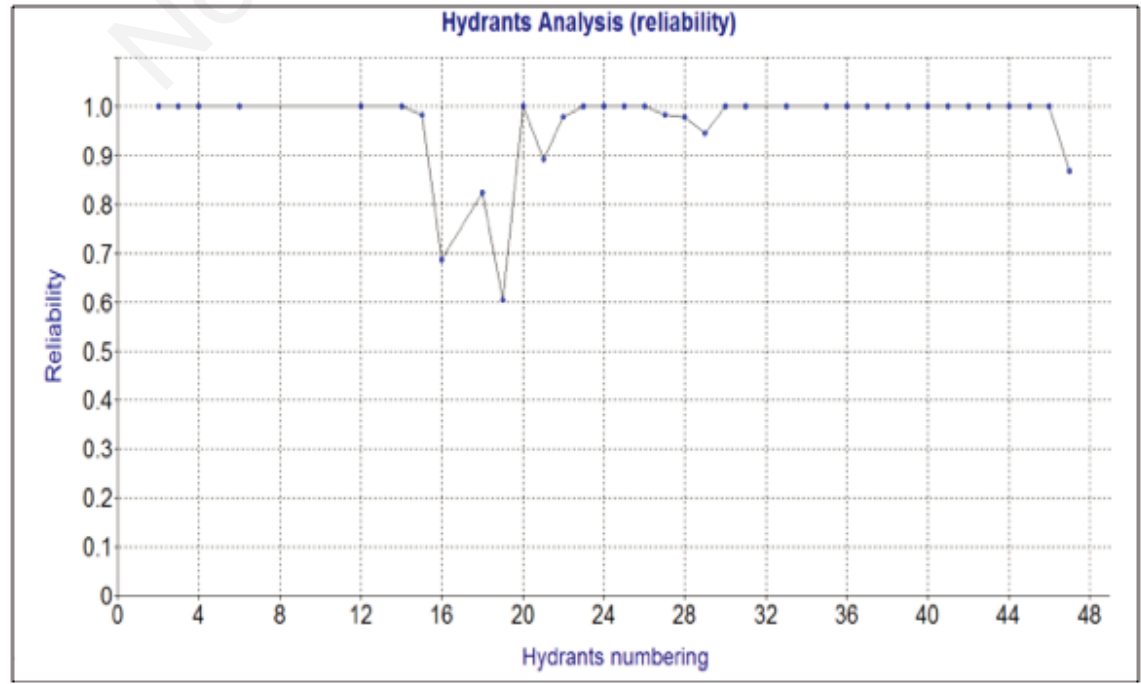

Figure 15. Reliability results using 200 random configurations, $Q_{0}=781 / s$ and $Z_{0}=100 \mathrm{~m}$ a.s.l. 


\section{Conclusions and recommendations}

The performance analysis of the on-demand pressurized irrigation system of sector 6 of district 10 in 'Sinistra Ofanto' irrigation scheme was carried out.

The performance analysis was conducted using COPAM, which proved useful for the evaluation of performance of the ondemand irrigation systems, as it identified and quantified the operation deficiencies in the system through two conceptual models: the indexed characteristic curves model and AKLA model.

However, in many cases, some input data, such as the water volumes delivered at hydrants, are not readily available. To support a wider application of COPAM, the possibility of using irrigation volumes estimated by means of space-borne remote sensing was tested in this study. The Sentinel-2 constellation provides high spatial resolution images with a frequency between 2 and 5 days, which is compatible with the input requirements of COPAM.

In a first step, the available Sentinel-2 images were collected for the study period from June $1^{\text {st }}$ to September $30^{\text {th }} 2019$ and then processed. Using QGIS, the crop parameters maps were created and generated. By combining the results derived from the maps and the meteorological data from the ERA5 single level reanalysis dataset, the crop evapotranspiration (Etc $\mathrm{rop}_{\mathrm{p}}$ ) and effective precipitation $\left(\mathrm{P}_{\mathrm{n}}\right)$ were estimated. Subsequently, the estimation of the irrigation water requirement volumes was completed.

In a second step, since the registered volumes were available at hydrant level, the estimated and registered irrigation volumes required by each crop were summed up for the entire sector and followed by a comparison of the volumes. The results showed a good agreement between the estimated and the registered volumes in a large time scale for 10 days and a one-month period. On the contrary, a large difference was observed on a daily time scale, because the estimation was entirely based on satellite images and meteorological data, and did not take into account the operation of the distribution network.

In a third step, the performance analysis of the studied irrigation system was assessed. The results from the indexed characteristic curves model revealed that $90 \%$ of the investigated configurations were fully satisfied using the estimated upstream discharge, while only $85 \%$ of the investigated configurations were fully satisfied using the registered upstream discharge. As to the AKLA model results, the relative pressure deficit indicator showed that, using the estimated upstream discharge, $14 \%$ of the hydrants were subject to an insufficient pressure head compared to $22 \%$ obtained with the registered upstream discharge. The reliability indicator also was considered, and better results were observed with the estimated upstream discharge.

Finally, the studied irrigation system showed good performance overall, except for hydrants in critical zones, which could still have insufficient pressure. In order to solve this problem, it is possible to: i) increase the pipe diameter upstream to the critical zone, so the head losses will be less and more pressure could be available at hydrant level; ii) install additional lifting units (booster pumps) downstream to the critical hydrants; iii) place upstream to the sector some special devices which can stop irrigation during the peak demand hours; iv) suggest that the farmers in critical areas avoid irrigating during peak hours.

The case study of sector 6 demonstrated that the estimation of the irrigation water requirement, and then the input discharge in COPAM, using Sentinel-2 images combined with the meteorological data, can describe the performance of the irrigation system. This information could be useful to irrigation managers to take the appropriate management decisions

\section{References}

Allen R.G., Pereira L.S., Raes D., Smith M. 1998. Crop evapotranspiration - guide- lines for computing crop water requirements. FAO irrigation and drainage paper, 56.:FAO, Rome, Italy.

Bacour C., Baret F., Beal D., Weiss M., Pavageau M.K. 2016. Neural network estimation of LAI, fAPAR, fCover and LAIxCab, from top of canopy MERIS reflectance data: Principles and validation. Remote Sens. Environ. 105:313-25.

Bastiaanssen, W. G. M. 1998. Remote sensing in water resources management: the state of the art. Colombo, Sri Lanka: International Water Management Institute (IWMI). ix, 118p.Available https://publications.iwmi.org/pdf/H022865.pdf

Bastiaanssen W.G., Molden D.J., Makin I.W. 2000. Remote sensing for irrigated agriculture: examples from research and possible applications. Agric. Water Manage. 46:137-55.

Braden H. 1985. Ein Energiehaushalts- und Verdunstungsmodell für Wasser- und Stoffhaushaltsuntersuchungen landwirtschaftlich genutzter Einzugsgebiete. Mitteilungen der Deutschen Bodenkundlichen Gesellschaft 42:294-9.

Bréda J.J.N. 2003. Ground-based measurments of leaf area index: a review of methods, instruments and current controversies. J. Exp. Botany 54: 2403-17.

Brutsaert W.H. 1982. Evaporation into the atmosphere. D. Reidel Publishing Company, Dordrecht, The Netherlands.

Clevers J.G.P.W. 1989. The application of a weighted infrared-red vegetation index for estimating leaf area index by correcting for soil moisture. Remote Sens. Environ. 29:25-37.

D'Urso G. 2001. Simulation and management of on-demand irrigation systems: a combined agrohydrological and remote sensing approach. PhD thesis. Wageningen University, Wageningen The Netherlands.

D’Urso G., Calera Belmonte A. 2006. Operative approaches to determine crop water requirements from Earth Observation data: methodologies and applications. AIP Conf. Proc. 852:1425.

D’Urso G., Richter K., Calera A., Osann M.A., Escadafal R., Garatuza-Pajan J. Hanich L., Perdigão A., Tapia J.B., Vuolo F. 2010. Earth Observation products for operational irrigation management in the context of the PLEIADeS project. Agric. Water Manage. 98:271-82.

Estrada C., González C., Aliod R., Paño J. 2009. Improved pressurized pipe network hydraulic solver for applications in irrigation systems. J. Irrig. Drain. Engine. 135(4).

Hersbach H., Bell B., Berrisford P., Biavati G., Horányi A., Muñoz Sabater, J., Nicolas J., Peubey C., Radu R., Rozum I., Schepers D., Simmons A., Soci C., Dee D., Thépaut J-N. 2018. ERA5 hourly data on single levels from 1979 to present. Copernicus Climate Change Service (C3S) Climate Data Store (CDS). doi:10.24381/cds.adbb2d47

Kurtulmus E., Büyükcangaz H., Kusçu H. and Demir O.A. 2018. The hydraulic and economic performance analysis of ondemand pressurized irrigation systems: a case study in Turkey. J. Agric. Sci. 24:42-9.

Lamaddalena N. 1997. Integrated simulation modeling for design and performance analysis of on-demand pressurized irrigation systems. PhD Thesis. Technical University of Lisbon, Lisbon, Portugal.

Lamaddalena N., Pereira L.S. 2007. Pressure-driven modeling for performance analysis of irrigation systems operating on demand. Agric. Water Manag. 90:36-44.

Lamaddalena N., Sagardoy J.A. 2000. Performance analysis of ondemand pressurized irrigation systems. FAO irrigation and 
drainage paper, 59. FAO, Rome, Italy.

Ozdogan M., Yang Y., Allez G., Cervantes C. 2010. Remote sensing of irrigated agriculture: opportunities and challenges. Remote Sens. 2:2274-304.

Pelosi A., Terribile F., D’Urso G., Chirico B.G. 2020. Comparison of ERA5-Land and UERRA MESCAN-SURFEX reanalysis data with spatially interpolated weather observations for regional assessment of reference evapotranspiration. Water $12: 1669$

Rolim J., Navarro A., Vilar P., Saraiva C., Catalao J. 2019. Crop data retrieval using earth observation data to support agricultural water management. Eng. Agríc. 39:380-90.

Rossman L.A. 2000. EPANET 2. Users Manual. Water supply and Water Resources Division National Risk Management Research Laboratory. U.S. Environmental Protection Agency,
Cincinnati, OH, USA.

UNWAP (United Nations World Water Assessment Programme). 2016. Water and jobs. World Water Development Report 2016. UNESCO, Paris, France.

Vanino S., Pulighe G., Nino P., De Michele C., Bolognesi S.F., D'Urso G. 2015. Estimation of evapotranspiration and crop coefficients of tendone vineyards using multi-sensor remote sensing data in a Mediterranean environment. Remote Sens. 7:14708-30.

Vuolo F., D’Urso G., De Michele C., Bianchi B., Cutting M. 2015. Satellite-based irrigation advisory services: a common tool for different experiences from Europe to Australia. Agric. Water Manage. 147:82-95. 